\title{
The Effect of Type 1 IFN on Human Aortic Endothelial Cell Function In Vitro: Relevance to Systemic Lupus Erythematosus
}

\author{
John A. Reynolds, ${ }^{1}$ David W. Ray, ${ }^{2}$ Leo A.H. Zeef, ${ }^{3}$ Terence O'Neill, \\ Ian N. Bruce, ${ }^{1,4}$ and M. Yvonne Alexander ${ }^{5}$
}

Cardiovascular disease (CVD) is an important cause of morbidity and mortality in patients with systemic lupus erythematosus. The etiopathogenesis of premature CVD is not fully understood, but recently interferon-alpha (IFN $\alpha$ ) has been implicated as a contributing factor. Since IFN $\alpha$ has been associated with both disease activity and endothelial dysfunction in lupus patients, we aimed to determine whether IFN $\alpha$ has direct effects on human aortic endothelial cell (HAoEC) function in vitro. We studied the function of IFN $\alpha 2 b$-treated HAoECs in terms of cell proliferation, capillary-like network formation, and nitric oxide (NO) generation. Changes in gene expression were also analyzed using an exon gene array. IFN $\alpha 2 b$ regulated the expression of 198 genes, including recognized interferon-stimulated genes (ISGs). Gene ontology analysis showed over-representation of genes involved in antigen presentation and host response to virus but no significant changes in clusters of genes recognized as important in endothelial cell activation or dysfunction. HAoEC proliferation, tubule formation, and NO bioavailability were unchanged, suggesting that IFN $\alpha$ in isolation does not have a direct impact on aortic endothelial cell function.

\section{Introduction}

$\mathrm{P}$ ATIENTS WITH SYSTEMIC lupus erythematosus (SLE) have a significantly increased risk of premature cardiovascular disease (CVD), which is not fully explained by traditional cardiovascular risk factors (Ward 1999). In addition to clinical cardiovascular events, there is an increased prevalence of subclinical CVD. We have previously demonstrated that lupus patients have endothelial dysfunction, when compared to age- and sex-matched healthy controls, even in the absence of clinical CVD (El-Magadmi and others 2004).

Interferon-alpha (IFN $\alpha)$ is an important pro-inflammatory cytokine in SLE, produced by activated plasmacytoid dendritic cells and neutrophils (Denny and others 2010; Trinchieri 2010). The expression of IFN-stimulated genes (ISGs) within blood mononuclear cells from lupus patients is associated with disease activity (Feng and others 2006;
Hua and others 2006). The combination of genes reported as forming this "interferon-signature" is variable, but commonly contains MX1, PRKR, IFIT1, and IFI44. The expression of $M X 1$ directly correlates with endothelial dysfunction in SLE, as measured by peripheral arterial tonometry (Lee and others 2007). Recently, in a principal component analysis of 5 commonly used ISGs, specific individual genes were associated with the different measures of subclinical CVD in lupus patients (Somers and others 2012).

The mechanism by which IFN $\alpha$ induces endothelial dysfunction is unknown. Pharmacological doses of IFN $\alpha 2 b$ rapidly result in the development of endothelial dysfunction and reduced exercise tolerance in patients with hepatitis $\mathrm{C}$ (Takase and others 2001). A direct effect of IFN on the endothelium is supported by the observation that endothelial cell biopsies from lupus patients strongly express ISGs (IFIT3, IFI44L, IFI6, MX2, IFIT1, OAS1, and OAS2) (Goldenberg and others 2011). This suggests a functioning

\footnotetext{
${ }^{1}$ Arthritis Research UK Epidemiology Unit, Institute of Inflammation and Repair, Manchester Academic Health Sciences Centre, The University of Manchester, Manchester, United Kingdom.

${ }^{2}$ Endocrine Sciences Research Group, Institute of Human Development, Manchester Academic Health Science Centre, The University of Manchester, Manchester, United Kingdom.

${ }^{3}$ Bioinformatics Core Facility, Faculty of Life Sciences, The University of Manchester, Manchester, United Kingdom.

${ }^{4}$ NIHR Manchester Musculoskeletal Biomedical Research Unit, Kellgren Centre for Rheumatology, Central Manchester University Hospitals NHS Foundation Trust, Manchester Academic Health Science Centre, Manchester, United Kingdom.

${ }^{5}$ Institute of Cardiovascular Science, Core Technology Facility, Manchester Academic Health Science Centre, The University of Manchester, Manchester, United Kingdom.
} 
IFN receptor in the endothelium, which is able to respond to circulating IFN $\alpha$. Previous in vitro studies have demonstrated that IFN $\alpha$ induces cytokine expression, impairs tubule network formation and increases sensitivity to apoptosis in human venous endothelial cells (HUVECs) (Kaiser and others 2004; Tissari and others 2005; Cheng and others 2012). However, endothelial cell heterogeneity makes it difficult to extrapolate these results to cells derived from other vascular beds (Aird 2007). In terms of cellular proliferation, for example, IFN $\alpha$ has been shown to inhibit growth in dermal microvascular cells, while either increasing proliferation, or having no effect in HUVECs (Ruszczak and others 1990; Gomez and Reich 2003; Erdmann and others 2011). In studying the pathogenesis of CVD, the use of carotid, coronary, or aortic cells may be preferable as atherosclerosis develops in the arterial system in human subjects. Patients with SLE have a markedly increased prevalence of aortic atherosclerosis compared with healthy controls (Roldan and others 2010). Therefore, the aim of this study was to identify the effects of IFN $\alpha$ on arterial endothelial cells to determine whether IFN can directly contribute to endothelial dysfunction in patients with SLE.

\section{Materials and Methods}

Human aortic endothelial cells (HAoECs) from 2 individual donors (Promocell) were cultured in a humidified environment at $37^{\circ} \mathrm{C}, 5 \% \mathrm{CO}_{2}$ in EGM-MV2 (Promocell) supplemented with $5 \%$ foetal bovine serum (FBS), $100 \mathrm{U} / \mathrm{mL}$ penicillin, and $100 \mu \mathrm{g} / \mathrm{mL}$ streptomycin (Sigma-Aldrich). All proliferation and tubule formation experiments were carried out using HAoEC from > 2 individuals. HUVEC (Promocell) from pooled donors [cultured in EGM (Promocell) supplemented with 5\% (FBS) and antibiotics as above] were used as a comparator cell type in the proliferation/tubule formation studies. Experiments were conducted with cells at passages 3-9.

\section{Reverse-transcription polymerase chain reaction and microarray analysis}

Confluent HAoECs were serum-starved for $4 \mathrm{~h}$ and then fresh media $( \pm 10 \mathrm{ng} / \mathrm{mL}$ IFN $\alpha 2 \mathrm{~b}$ or vehicle) added for $6 \mathrm{~h}$. Cells were lysed using TRI Reagent ${ }^{\circledR}$ (Sigma-Aldrich) and RNA was extracted according to the manufacturer's protocol followed by treatment with DNase I (Ambion) at $37^{\circ} \mathrm{C}$ for $30 \mathrm{~min}$, to ensure removal of residual genomic DNA. The RNA pellet was precipitated and quantified using a NanoDrop ND-1000 spectrophotometer (NanoDrop Technologies). Reverse transcription of $1 \mu \mathrm{g}$ RNA was carried out using a Precision NanoScript Reverse Transcription kit (PrimerDesign) in a total volume of $20 \mu \mathrm{L}$.

Expression of the IFN-stimulated gene IFI44 and GAPDH (reference gene) was determined using $1 \mu \mathrm{L}$ cDNA according to the following protocol: Denature at $94^{\circ} \mathrm{C}$ for $5 \mathrm{~min}$, followed by 30 cycles of $94^{\circ} \mathrm{C}$ for $20 \mathrm{~s}, 59^{\circ} \mathrm{C}$ for $40 \mathrm{~s}, 72^{\circ} \mathrm{C}$ for $40 \mathrm{~s}$; and a final elongation step at $72^{\circ} \mathrm{C}$ for $7 \mathrm{~min}$. Primers used were IFI44 (Sense 5'-TTGGAGGGAAGCGGCT TAGCCT-3'; anti-sense 5'-TGGACCCAGCAGCAGAATT CGT-3') and GAPDH (Sense 5'-CCACCCATGGCAAATT CCATG-3'; anti-sense 5'-TCTAGACGGCAGGTCAGGTC CACC- $3^{\prime}$ ). Polymerase chain reaction products were run on a $1 \%$ agarose gel containing $0.05 \%$ (w/v) ethidium bromide at $100 \mathrm{~V}$ for $40 \mathrm{~min}$. The result of this was used to identify a suitable concentration of IFN $\alpha 2 b$ for the genome wide analysis below.

For the exon gene array, the integrity and purity of the RNA was confirmed by RNA 6000 NanoAssay on an Agilent 2100 Bioanalyzer. All RNA samples had a RNA integrity number >9.90. An Affymetrix GeneChip Human Exon 1.0 ST Array (version 2.0) was performed using $50 \mathrm{ng}$ RNA from IFNtreated $(10 \mathrm{ng} / \mathrm{mL}$ IFN $\alpha 2 \mathrm{~b}$ for $6 \mathrm{~h})$ or vehicle-treated HAoECs from 2 independent experiments. Microarray data quality, normalization, and expression analysis were assessed using Affymetrix GCOS software, dChip, and RMA (Li and others 2001). Further statistical analysis of the dataset, including Principal Components Analysis and $t$-tests, were performed using maxdView (available from http:/bioinf.man.ac.uk/microarray/maxd/). Differentially expressed genes were defined as those with a fold-change $\geq 2$ and a mean fluorescence signal intensity of $>50$ for at least 1 of the treatment groups. Significance was defined as a $q \leq 0.2$ (with Bonferroni correction to adjust for the effect of multiple comparisons). Gene ontology (GO) analysis was performed using the online DAVID Functional Annotation Tool (Huang and others 2009). Normalized data files are available on the ArrayExpress Website under the reference E-MEXP-3746 (www.ebi.ac.uk/ arrayexpress/experiments/E-MEXP-3746/).

\section{Proliferation studies}

HAoECs were seeded at $1 \times 10^{4} / \mathrm{cm}^{2}$ into 24-well culture plates containing $9 \mathrm{~mm}$ diameter glass coverslips (Nunc) and allowed to adhere overnight. Cells were serum-starved for $4 \mathrm{~h}$ (EGM-MV2 with no FBS) and then cultured for up to $72 \mathrm{~h}$ in the presence of $10 \mathrm{ng} / \mathrm{mL}$ IFN $\alpha 2 \mathrm{~b}$ (Promokine) or vehicle control, in triplicate, in EGM-MV2 5\% FBS. At each time point $(0,24,48$, and $72 \mathrm{~h})$ triplicate coverslips were removed, fixed in $5 \%$ trichloracetic acid for $30 \mathrm{~min}$, stained with Mayer's hematoxylin for $5 \mathrm{~min}$, and rinsed for a further $5 \mathrm{~min}$ in running tap water. Coverslips were then mounted onto glass slides and 3 random fields per coverslip were visualized at $\times 100$ magnification using a Leica CTR 5000 microscope and Leica DFC320 color camera. The number of nuclei per field was counted using ImageJ software (http://rsb.info.nih.goc/ij).

Cell proliferation and mitochondrial activity was also measured using Cell Proliferation Kit 1 (MTT) (Roche) according to the manufacturer's instructions. Briefly, $1 \times 10^{4} / \mathrm{cm}^{2}$ HAoECs or HUVECs were cultured in 96-well plates in the presence of IFN $\alpha 2 \mathrm{~b}(0.1-10 \mathrm{ng} / \mathrm{mL})$ for up to $72 \mathrm{~h}$. At each $24 \mathrm{~h}$ time point, triplicate wells were incubated with $50 \mu \mathrm{g}$ 3-[4,5-dimethylthiazol-2-yl]-2,5-diphenyltetrazolium bromine (MTT) for $4 \mathrm{~h}$ at $37^{\circ} \mathrm{C}$, and the resulting purple formazan crystals solubilized with $10 \%$ sodium dodecyl sulfate (SDS) in $0.01 \mathrm{M} \mathrm{HCl}$ overnight. Plates were then read at wavelength 570 and $750 \mathrm{~nm}$ (referent) using a BioTek EL800 plate reader running Gen5 software (BioTek Instruments). Vascular endothelial growth factor A (VEGF-A; $20 \mathrm{ng} / \mathrm{mL}$ ) (Promokine) and the nitric oxide (NO) scavenger PTIO (as carboxy-PTIO potassium salt) $(10 \mu \mathrm{M})$ (Sigma-Aldrich) were used as positive and negative controls respectively.

\section{NO bioavailability}

HAoECs were plated at $2.5 \times 10^{4}$ cells $/ \mathrm{cm}^{2}$ in 24 -well plates and cultured until $90 \%$ confluent. The media $(500 \mu \mathrm{L})$ 
was replaced with fresh EGM-MV2 containing $0.1-10 \mathrm{ng} / \mathrm{m}$ IFN $\alpha 2 b$ in triplicate, and then removed at 6 or $24 \mathrm{~h}$. Total nitrite concentration was determined using the nitrate/nitrite colorimetric assay kit (Cayman Chemical Company) according to the manufacturer's protocol and read at $550 \mathrm{~nm}$. This assay contains nitrate reductase, which converts all available nitrate to nitrite and can detect nitrite concentration of $2.5 \mu \mathrm{M}$, providing an indirect measure of NO bioavailability.

\section{Tubule formation assays}

The ability of endothelial cells to form tubule networks on a gel matrix forms the basis of numerous in vitro angiogenesis assays. It is well recognized that the formation of these networks is dependent, at least in part, on the matrix used. It is recommended, therefore, that the effect of test substances is determined on more than 1 matrix (Staton and others 2009). We therefore investigated the effects of IF$\mathrm{N} \alpha 2 \mathrm{~b}$ in both Matrigel [two-dimensional (2D) networks] and type 1 collagen [three-dimensional (3D) networks].

To assess $2 \mathrm{D}$ tubule formation, initially $6 \times 10^{3} \mathrm{HAoECs}$ in $100 \mu \mathrm{L}$ EGM-MV2 $\pm 10 \mathrm{ng} / \mathrm{mL}$ IFN $\alpha 2 \mathrm{~b}$ were placed onto $30 \mu \mathrm{L}$ Matrigel $^{\mathrm{TM}}$ (BD Biosciences), which had been allowed to polymerize in 96 -well culture plates at $37^{\circ} \mathrm{C}$ for $30 \mathrm{~min}$. Subsequent experiments used $3.5 \times 10^{3} \mathrm{HAoEC}$ or $5 \times 10^{3}$ HUVEC in $50 \mu \mathrm{L}$ media placed onto $10 \mu \mathrm{L}$ Matrigel in Angiogenesis $\mu$-Slides (IBIDI). Tubule network formation was observed at $16 \mathrm{~h}$ using an Olympus CKX41 microscope and Olympus C-7070 camera. Images were imported into Image J software and the density of the network was determined by the number of branch points/junctions in 3 random fields per well.

To examine 3D tubule formation, a collagen gel was prepared using a method adapted from Abaci and others (2011). Briefly, an alkaline solution [102.225 $\mu \mathrm{L}$ DMEM $(1 \times), 9.75 \mu \mathrm{L}$ DMEM $(10 \times)$, and $0.525 \mu \mathrm{L} 5 \mathrm{~N} \mathrm{NaOH}]$ was carefully mixed with a gel solution $[72.2 \mu \mathrm{L}$ type 1 rat tail collagen (BD Biosciences) and $15.25 \mu \mathrm{L} 0.1 \%$ acetic acid] on ice. HAoECs were resuspended in DMEM $(1 \times)$ and added to the gel solution to make a final cell concentration of $1.1 \times 10^{6}$ cells $/ \mathrm{mL}$ and collagen concentration of $1.4 \mathrm{mg} /$ $\mathrm{mL}$. The cell suspension was added to 96-well plates $\left(53.8 \mu \mathrm{L} /\right.$ well), incubated at $37^{\circ} \mathrm{C}$ for $10 \mathrm{~min}$, and then $100 \mu \mathrm{L}$ EGM-MV $2 \pm 10 \mathrm{ng} / \mathrm{mL}$ IFN $\alpha 2 \mathrm{~b}$ added and tubule formation assessed at $48 \mathrm{~h}$.

\section{Statistical analysis}

Data were analyzed using GraphPad Prism version 6.00. Differences in the functional assays were compared using paired $t$-tests (proliferation and tubule formation) and oneway ANOVA (NO assay).

\section{Results}

\section{Transcriptional analysis of IFN $\alpha 2 b$ in HAoECs}

Exposure of HAoECs to IFN $\alpha 2 b(0.1-10 \mathrm{ng} / \mathrm{mL})$, but not tumor necrosis factor-alpha $(\mathrm{TNF} \alpha)(10 \mathrm{ng} / \mathrm{mL})$, for $6 \mathrm{~h}$ resulted in increased expression of the ISG IFI44 (Fig. 1A, B). The genome wide analysis by Affymetrix GeneChip Exon array showed that IFN $\alpha 2 b$ had a significant effect on gene expression in HAoECs. A total of 198 genes were signifi- cantly regulated by IFN (fold change $\geq 2 ; q<0.2$ ) although of these only $5 / 198(2.5 \%)$ were downregulated.

GO analysis was performed to classify the 198 genes according to their biological function. The largest group of transcripts regulated by IFN $\alpha 2 b$ were those involved in immune system function (62 genes) followed by genes related to transcription and translation (26 genes) and intracellular signaling pathways (24 genes) (Fig. 1C). Within the immune-related group, 14 genes were involved in inhibition of viral replication (Fig. 1D).

The ISGs IFIT1 and IFI44L were among the upregulated genes and expression was increased by 122.4- and 93.1-fold respectively. Genes upregulated by $\geq 15$-fold are presented in Figure 1E and include recognized ISGs (IFIT1, IFI44L, IFIT3, MX1, MX2, OAS1, and OAS2).

To demonstrate that this endothelial model was robust an identical exon array was also performed using TNF $\alpha$ (10 ng/ $\mathrm{mL}$ ) (Heathfield and others 2012). In contrast to IFN $\alpha 2 b$, $\mathrm{TNF} \alpha$ differentially regulated 11,327 genes $(q \leq 0.2)$ with $\geq 2$-fold changes in 206 genes (Fig. 2A). Only 20 genes were upregulated by both TNF $\alpha$ and IFN $\alpha 2$ b by $\geq 2$-fold including recognized ISGs; MX1, IFIT3, and IFI30 (Fig. 2B).

\section{Effect of IFN $\alpha 2 b$ on endothelial cell proliferation and NO availability}

The number of HAoECs in random fields increased over the time course, demonstrating that the cell culture conditions were adequate for cellular proliferation. IFN $\alpha 2 b$ $(10 \mathrm{ng} / \mathrm{mL})$ had no effect on the number of cells counted at 24, 48, or $72 \mathrm{~h}$ (Fig. 3A), indicating no effect on HAoEC proliferation.

The effect of IFN $\alpha 2 b$ on HAoEC proliferation was also measured using an MTT assay. HUVECs were used as a comparator cell population. VEGF-A $(20 \mathrm{ng} / \mathrm{mL})$ and carboxy-PTIO $(10 \mu \mathrm{M})$ were used as positive and negative control treatments respectively. After $24 \mathrm{~h}$, in both HAoEC and HUVEC there was a significant increase in proliferation in VEGF-A-treated cells ( $P=0.022$ for both cell types) and a significant decrease in PTIO-treated cells $(P=0.002$ and $P=0.007$, respectively) (Fig. 3B). IFN $\alpha 2 \mathrm{~b}(10 \mathrm{ng} / \mathrm{mL})$ had no effect on HAoEC proliferation at $24 \mathrm{~h}(P=0.210)$ but resulted in a small but significant increase in HUVEC proliferation $(P=0.047)$ at this time point. However, at 48 and $72 \mathrm{~h}$ IFN $\alpha 2 \mathrm{~b}$ had no significant effect on proliferation in either cell type (Fig. 3C, D), although the trend toward increased HUVEC proliferation was seen at $48 \mathrm{~h}$.

NO bioavailability was measured in the cell culture supernatant from HAoECs treated with either IFN $\alpha 2 b(0.1-$ $10 \mathrm{ng} / \mathrm{mL}$ ) or vehicle control. IFN $\alpha 2 \mathrm{~b}$ had no effect on the total nitrate and nitrite concentration at either 6 or $24 \mathrm{~h}$ ( $P=0.217$ and $P=2.78$ respectively) (Fig. 3E).

\section{Effect of IFN $\alpha 2 b$ on endothelial tubule network formation}

Both HAoECs and HUVEC spontaneously formed capillary-like tubule networks in Matrigel. The addition of IFN $\alpha 2 b(10 \mathrm{ng} / \mathrm{mL})$ to the media did not have any significant effect on the density of HAoEC tubule network $(P=0.371)$ (Fig. 4A, B). Similar to the proliferation studies above, VEGF-A significantly increased the network density $(P=0.026)$ while carboxy-PTIO markedly impaired tubule 
A

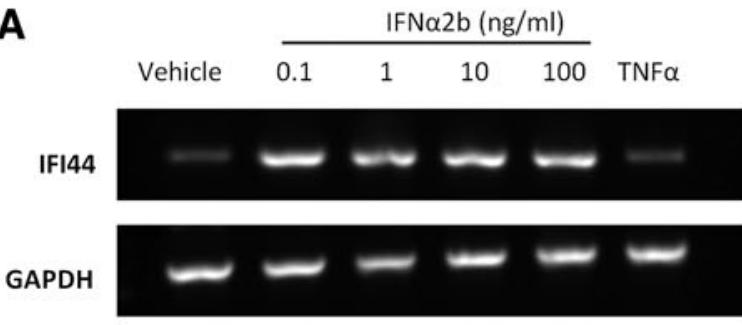

C

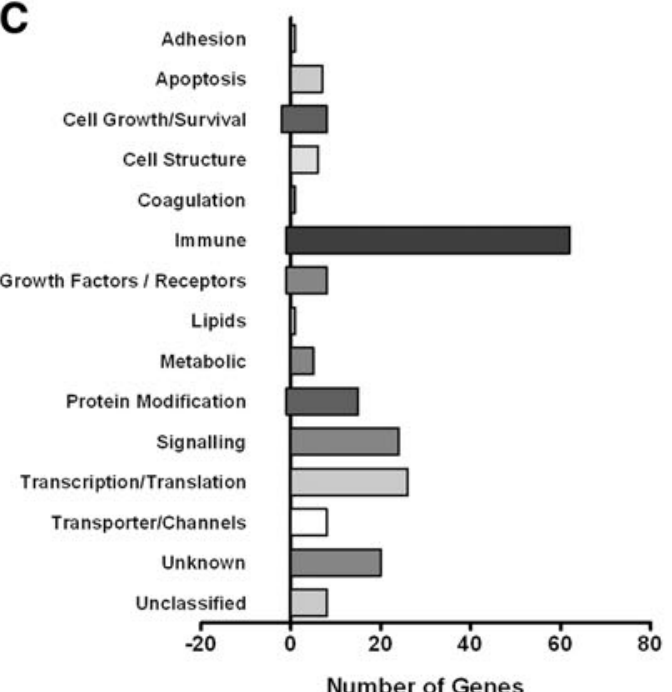

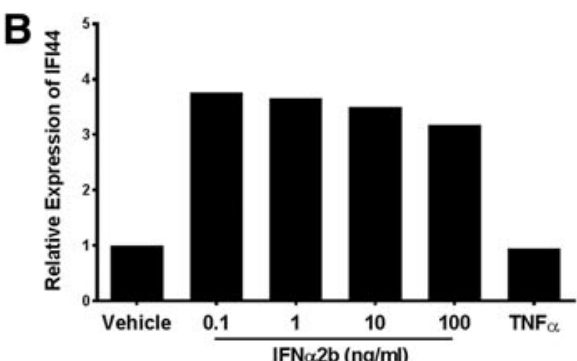

D Viral Replicatio Transporter/Channel Antigen Presentation Anti-microbial B/T Cell Fuction Complement Activation Chemotaxis DNA Clearance Cytoskeleton/membrane Gene Expression Lipids Metabolic Proteolytic Receptors Redox Signalling

Transcription/Translation $-5$

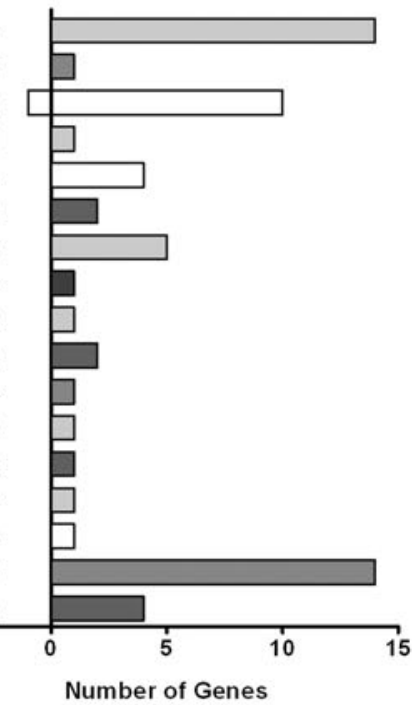

E

\begin{tabular}{|c|c|c|}
\hline Gene & $\begin{array}{c}\text { Fold Change (IFN vs Untreated } \\
\text { Control) }\end{array}$ & Functional Group \\
\hline IFIT1 & 122.4 & Immune / Viral Replication \\
\hline IFI44L & 93.1 & Immune / Cell Signalling \\
\hline CXCL10 & 96.1 & Immune/Chemotaxis \\
\hline CXCL11 & 89.1 & Immune/Chemotaxis \\
\hline IFIT3 & 81.4 & Immune/Cell Signalling \\
\hline OAS2 & 58.9 & Immune / Viral Replication \\
\hline RSAD2 & 54.5 & Immune/Cytoskeleton/Membrane \\
\hline $\mathrm{M} \times 2$ & 49.3 & Immune/Cell Signalling \\
\hline IFIT2 & 35.8 & Immune / Cell Signalling \\
\hline OAS1 & 32.9 & Immune/Viral Replication \\
\hline MX1 & 32.2 & Immune/Transporter/Channel \\
\hline GBP4 & 30.7 & Cell Signalling \\
\hline IFI44 & 27.7 & Cytoskeleton \\
\hline HERC6 & 25.9 & Protein Modification \\
\hline EPSTI1 & 25.3 & Unknown \\
\hline IFIH1 & 19.5 & Immune/Viral Replication \\
\hline HERC5 & 17.5 & Protein Modification \\
\hline TLR3 & 17.0 & Immune/Receptor \\
\hline OAS3 & 15.3 & Immune / Viral Replication \\
\hline
\end{tabular}

FIG. 1. Gene expression in human aortic endothelial cell (HAoEC) in response to IFN $\alpha 2 b$. (A) IFN $\alpha 2 b(0.1-100 \mathrm{ng} / \mathrm{mL})$ but not tumor necrosis factor-alpha $(\mathrm{TNF} \alpha)(10 \mathrm{ng} / \mathrm{mL})$ increases expression of the interferon-sensitive gene IFI44. Reverse transcription-PCR products shown for IFI44 and the reference gene GAPDH. (B) The fold change in IFI44 was similar across doses of IFN. (C) Gene ontology (GO) analysis of 198 differentially expressed transcripts by IFN $\alpha 2 \mathrm{~b}$ (fold $\geq 2, q \leq 0.2$ ) according to biological function reveals over-representation of genes with immunoregulatory function. (D) A more detailed GO analysis of the 63 genes initially assigned to immune function group shows marked expression of genes involved in viral replication and antigen presentation. (E) Tabulation of genes upregulated by IFN $\alpha 2$ b by $\geq 15$-fold includes the recognized ISGs IFIT1, IFI44L, and MX1. 


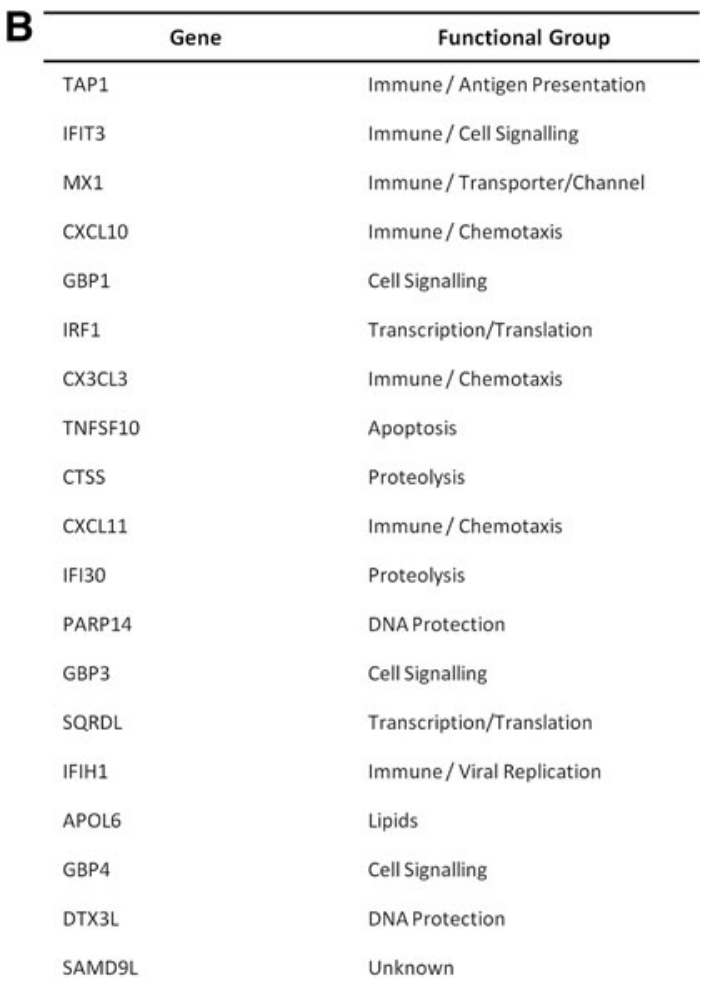

FIG. 2. HAoEC gene expression in response to IFN $\alpha 2 b$ and $T N F \alpha$. (A) Venn diagram to show number of genes significantly upregulated by both IFN $\alpha 2 \mathrm{~b}$ and $\mathrm{TNF} \alpha$ in the exon gene arrays. (B) The expression of 20 genes is significantly upregulated by both cytokines.

formation by $>50 \%(P=0.001)$ (Fig. 4B). IFN $\alpha 2 \mathrm{~b}$ also had no effect on the tubule-forming capacity of HUVEC $(P=0.339)$ (Fig. 4C). HAoEC formed smaller, less wellconnected tubules in a type 1 collagen matrix (Fig. 4D). These networks are more difficult to accurately quantify, although no effect of IFN $\alpha 2 b$ was seen.

\section{Discussion}

IFN $\alpha$ induced the expression of known ISGs in aortic endothelial cells. This interferon signature was comparable to that seen in endothelial biopsies of lupus patients (Goldenberg and others 2011), in peripheral blood cells (Baechler 2003), and in epithelial cell lines following treatment with lupus patient serum (Hua and others 2006). The gene expression profile is dominated by genes involved in immune system regulation; particularly viral replication (IFIT1, OAS2, and OAS1), leukocyte chemotaxis (CXCL10 and CXCL11), and intracellular signaling (IFIT3, MX2, and IFIT2). These observations support the role of IFN $\alpha 2 b$ in the host response to viral infection. The principal component analysis by Somers and others (2012) showed that PRKR expression alone was associated with endothelial dysfunction, while components including IFIT1, IFI4, and MXI were more strongly associated with carotid intima medial thickness and coronary calcification. Our transcriptional analysis did not show any direct regulation of PRKR expression in aortic endothelial cells. Similarly, lupus patient endothelial biopsies had downregulated genes in the TGF $\beta$ pathway, which again were not seen in our array. Our results suggest that these changes are not due to the direct effect of IFN on endothelial cells and may represent the effects of other cytokines.
Interestingly, some of the ISGs were also regulated by $\mathrm{TNF} \alpha$, although the fold expression changes were lower. The "IFN signature" itself may therefore not be exclusive to type 1 interferon and may be influenced by other inflammatory cytokines. In contrast to the effect of TNF $\alpha$ on HAoECs (Heathfield and others 2012), within the 198 genes significantly regulated by IFN, those associated with endothelial cell activation (eg, vascular cell adhesion molecules) were notably absent.

We found that despite significant upregulated expression of ISGs in HAoECs, IFN $\alpha$ had no significant effect on HAoEC function in an isolated culture system. We performed a comprehensive assessment of endothelial function in terms of proliferation, NO production and tubule forming capacity using multiple methodologies. It is possible that cellular response to IFN $\alpha$ is determined by the origin of the endothelial cell. For example, the induction of ISGs by IF$\mathrm{N} \alpha 2 \mathrm{~b}$, differs between lymphatic- and blood vessel-derived endothelial cells (Moll and others 2011). Previous studies in human cells have primarily focused on dermal microvascular cells (Ruszczak and others 1990; Sgonc and others 1998) or HUVECs (Eguchi and others 1992; da Silva and others 2002; Gomez and Reich 2003; Tissari and others 2005); however, these may be less relevant to models of endothelial dysfunction and atherosclerosis.

The effects of IFN $\alpha$ on HUVECs remains unclear; we found a small increase in proliferation at $24 \mathrm{~h}$ that persisted (although not significantly) at $48 \mathrm{~h}$. This is consistent with a previous study (Gomez and Reich 2003), although others have shown no effect (Erdmann and others 2011), or even inhibition of proliferation (Wang and others 2008; Wada and others 2009). More intriguingly, our proliferation assay 


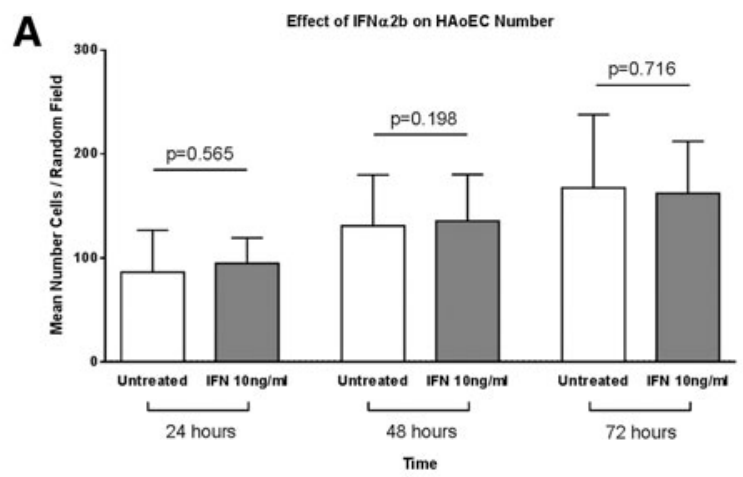

B Effect of IFN $\alpha 2 b$ on Cell Proliferation (MTT Assay) after 24 Hours

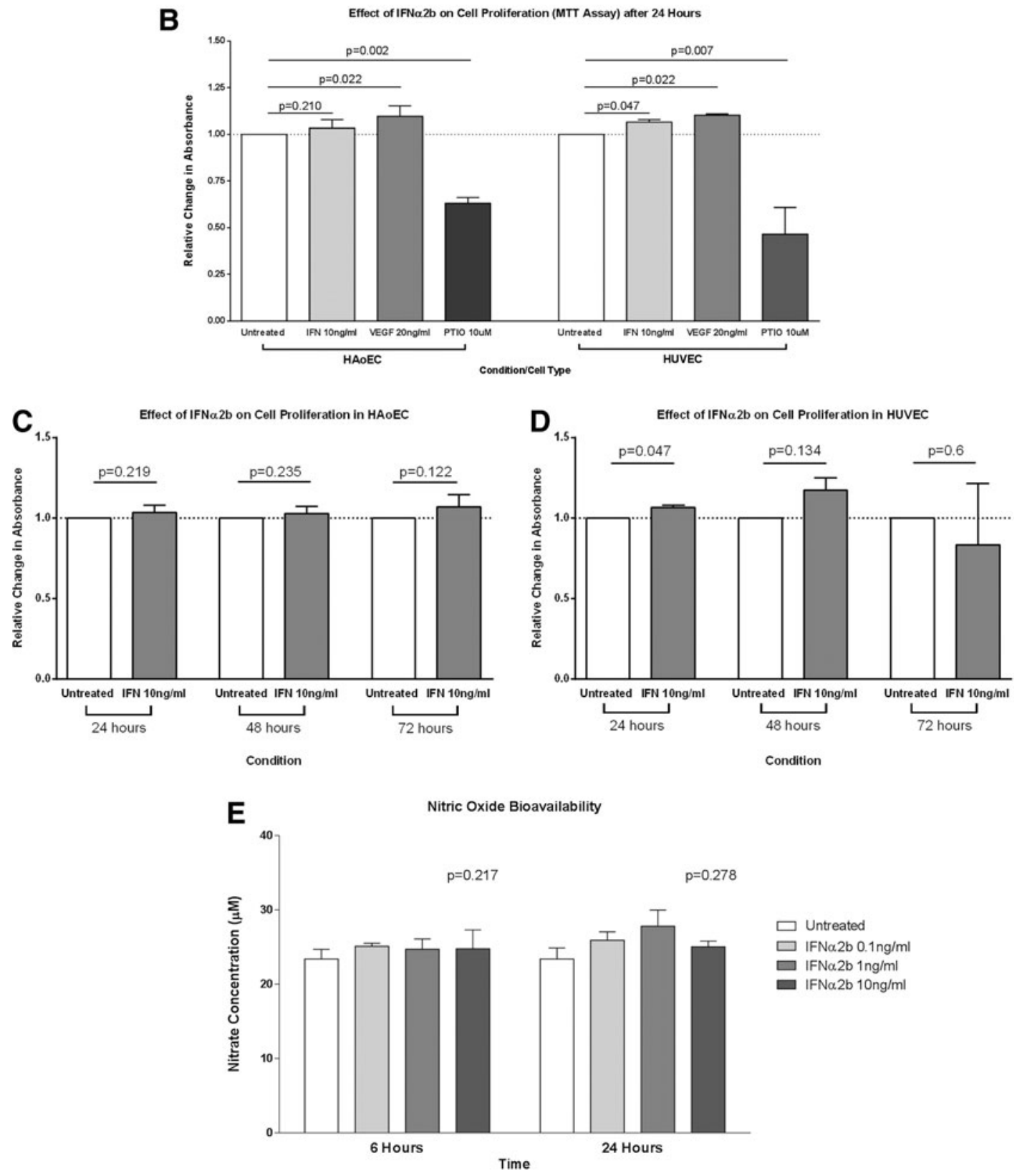

FIG. 3. The effect of IFN $\alpha 2 b$ on endothelial cell proliferation and nitric oxide (NO) bioavailability. (A) IFN $\alpha 2 b$ had no effect on the number of HAoECs at 24,48 , or $72 \mathrm{~h}$ compared to vehicle control. Bars represent the mean and SE of the mean; combined results from $n=3$ independent experiments. (B) Cellular proliferation as measured by MTT assay shows a positive effect of vascular endothelial growth factor (VEGF) $(20 \mathrm{ng} / \mathrm{mL})$ and a negative effect of the NO scavenger PTIO $(10 \mu \mathrm{M})$ on proliferation in both HAoEC and human venous endothelial cell (HUVEC) after $24 \mathrm{~h}$. The absorbance values were normalized to vehicle-treated cells. (C) IFN $\alpha 2 \mathrm{~b}(10 \mathrm{ng} / \mathrm{mL})$ had no effect on proliferation compared to vehicle control in HAoEC at 24, 48, or $72 \mathrm{~h}$. (D) In contrast, IFN $\alpha 2 \mathrm{~b}$ significantly increased HUVEC proliferation at $24 \mathrm{~h}(P=0.047)$. This effect persisted to $48 \mathrm{~h}$ but was not statistically significant $(P=0.134)$ at this time point. (E) The NO bioavailability (as measured by supernatant nitrite concentration) was not changed by IFN $\alpha 2 \mathrm{~b}(0.1-10 \mathrm{ng} / \mathrm{mL})$ at either 6 or $24 \mathrm{~h}$. 
A
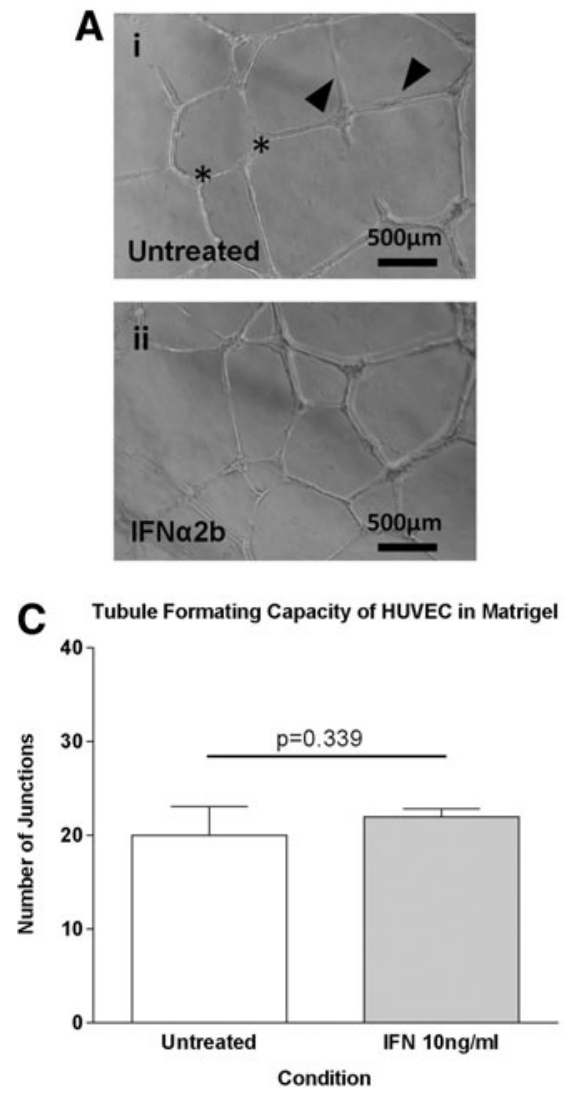

B

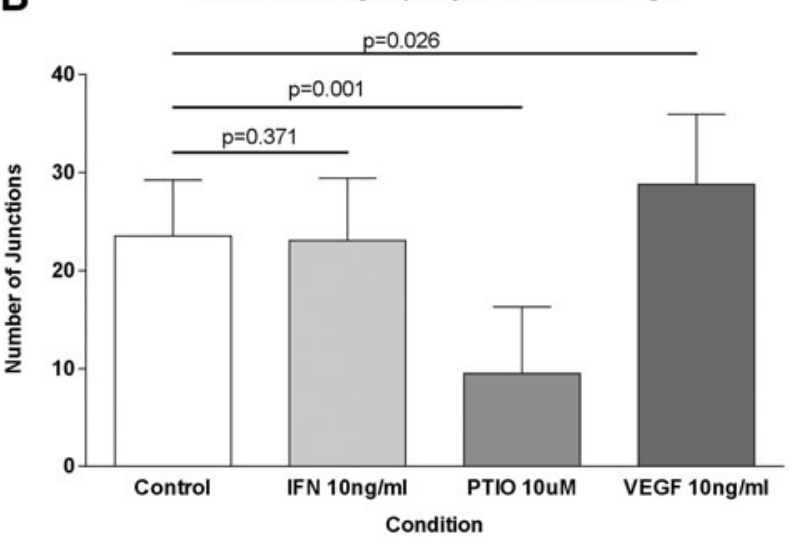

D

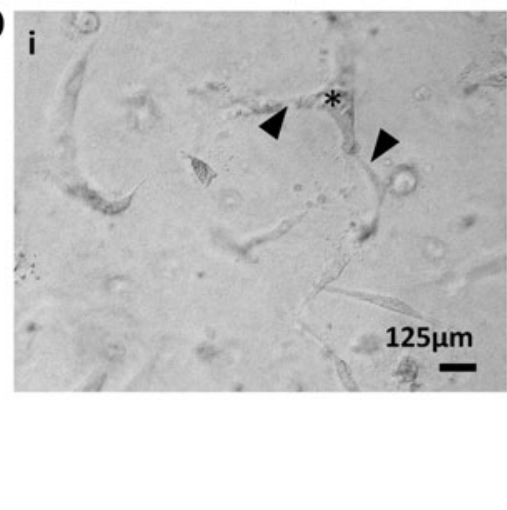

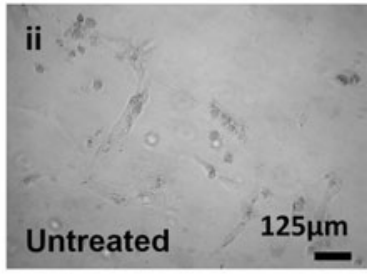

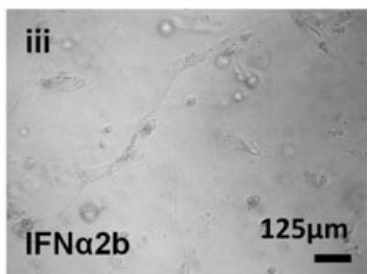

FIG. 4. The effect of IFN $\alpha 2 b$ on endothelial cell tubule network formation. (A) HAoEC formed tubule networks in Matrigel with clear branches (arrowheads) and branch points/junctions (star). Network density was determined by the number of junctions in 3 random fields. Each experimental condition was conducted in triplicate and each graph represents $n>3$ independent experiments. Bars represent the mean (SE) number of junctions. (B) The density of the HAoEC network was significantly increased by $10 \mathrm{ng} / \mathrm{mL}$ VEGF-A $(P=0.026)$ and decreased by $10 \mu \mathrm{M}$ carboxy-PTIO $(P=0.001)$. IFN $\alpha 2 \mathrm{~b}$ $(10 \mathrm{ng} / \mathrm{mL})$ had no effect on the HAoEC network density. (C) Similarly, the network density was not changed in HUVEC. Similar positive and negative effects of VEGF-A and PITO were seen in HUVEC (data not shown). (D-i) HAoEC tubule networks in three-dimensional (3D) type 1 collagen matrix were less complex than those on Matrigel. Representative image to show branch points/junctions (star) and branches (arrowheads). (D-ii, iii) Representative images of HAoEC networks in the presence of IFN $\alpha 2 \mathrm{~b}(10 \mathrm{ng} / \mathrm{mL})$ or vehicle control show no difference in tubule network structure or density.

shows a difference in response to IFN $\alpha 2 b$ between HAoEC and HUVEC, while the effects of VEGF-A and PTIO were similar. It is well recognized that cells from different vascular beds exhibit marked differences in terms of function and gene expression in vitro (Craig and others 1998; Aitsebaomo and others 2008). Complicating matters further, molecular profiles may also differ between regions of the same vessel (Passerini and others 2004). Further discrepancies may be due to the use of fetal (HUVEC) and adult (HAoEC) cells. Transcriptomic analysis reveals differences in the expression profile between foetal and mature cells from the same vascular bed (Chen and others 2013). Our studies utilized HAoEC as this cell type is both arterial and mature adult is thus likely to most closely resemble those cells in which atherosclerosis develops in vivo.

Only the study by Gomez and Reich (2003) has investigated the effect of IFN $\alpha$ on human aortic cells. In these experiments IFN $\alpha$ A/D $(\sim 4 \mathrm{ng} / \mathrm{mL})$ increased HAoEC proliferation by around 3 -fold after $72 \mathrm{~h}$. However, in our experiments we did not see any effect on proliferation at concentrations of up to $10 \mathrm{ng} / \mathrm{mL}$ over the same time period. Possible explanations for this discrepancy include differences due to the splice variant of IFN used (IFN $\alpha 2 b$ versus IFN $\alpha 2 a$ ), a potential interaction between IFN $\alpha$ and the components of FBS, or in the measurement of proliferation (MTT versus ${ }^{3}[\mathrm{H}]$-thymidine incorporation). Our studies used IFN $\alpha 2 b$ as it is considered the most pluripotent of the IFN $\alpha$ family and is associated with endothelial dysfunction at pharmacological doses in vivo (Takase and others 2001). In the studies by Gomez and Reich (2003), HAoECs were cultured in basic media containing high concentrations of FBS (20\% compared to only $5 \%$ in our studies). Components of FBS are known to interact with test agents in experimental culture systems and so may positively modulate IFN $\alpha$ signaling when high concentrations of FBS are used (Ribereau-Gayon and others 1995; Ueyama and others 1995). Additionally, it is recognized that formazan-based assays (ie, MTT) reflect mitochondrial activity, while ${ }^{3}[\mathrm{H}]$-thymidine incorporation assays measure DNA replication, and that these 2 measures do not directly correlate with each other (Wittstock and others 2001). 
Recently, others have shown that IFN $\beta$ but not IFN $\alpha$ impairs proliferation of microvascular lung endothelial cells and HUVECs by causing cell cycle arrest (Erdmann and others 2011).

We propose therefore that type 1 interferons can impair endothelial function via different mechanisms; either direct endothelial toxicity (IFN $\beta$ ) or by inhibiting endothelial repair mechanisms (IFN $\alpha$ ). Circulating angiogenic cells (CACs) and endothelial progenitor cells (EPCs) have important roles in the repair of damaged vasculature and participate in angiogenesis both in vitro and in vivo. The first observation was that early-EPC colony forming units (CFUs) were fewer in patients with SLE compared to healthy controls (Lee and others 2007) supported by data from our group (Haque and others 2009). This phenomenon was associated with the increased expression of the ISG $M X 1$ and replicated by the addition of IFN $\alpha 2 b$ in vitro. Mixed CAC/EPC populations underwent apoptosis in the presence of IFN $\alpha$ and were driven toward a non-angiogenic phenotype (Denny and others 2007). Further, abnormal EPC function in lupus-prone NZB/ NZW mice was replicated in control animals (BALB/c) by the addition of IFN $\alpha$ in vitro (Thacker and others 2010). The detrimental effects of IFN $\alpha$ on EPC function have recently been investigated in vivo by the generation of lupus-prone IFN $\alpha \beta$-receptor knockout mice. These animals have increased numbers of EPCs and improved endothelial function compared with lupus-prone mice with a functioning IFN pathway (Thacker and others 2012).

In summary, the effects of IFN $\alpha$ on the development of vascular dysfunction and CVD in patients with SLE do not appear to be due to a direct effect upon the mature endothelium. Further work should focus on the role of IFN $\alpha$ in vascular repair mechanisms and the development of relevant in vitro models should instead be based upon CAC/EPC function.

\section{Acknowledgments}

We thank the Genomic Technologies Core Facility in the Faculty of Life Sciences at the University of Manchester for providing technical support and advice with regard to Affymetrix arrays. J.A.R. received funding from a NIHR Manchester Biomedical Research Centre (BRC) Clinical Research Training Fellowship and is a MRC Clinical Training Fellow supported by the North West England Medical Research Council Fellowship Scheme in Clinical Pharmacology and Therapeutics, which is funded by the Medical Research Council (grant number G1000417/94909), ICON, GlaxoSmithKline, AstraZeneca, and the Medicines Evaluation Unit. I.N.B. is a National Institute for Health Research (NIHR) Senior Investigator and is supported by Arthritis Research UK, The Manchester Academic Health Science Centre, the NIHR Biomedical Research Unit Funding Scheme, The NIHR Manchester Wellcome Trust Clinical Research Facility and the NIHR Manchester Biomedical Research Centre. The views expressed in this publication are those of the authors and not necessarily those of the NHS, the National Institute for Health Research or the Department of Health.

\section{Author Disclosure Statement}

No competing financial interests exist.

\section{References}

Abaci HE, Truitt R, Tan S, Gerecht S. 2011. Unforeseen decreases in dissolved oxygen levels affect tube formation kinetics in collagen gels. Am J Physiol Cell Physiol 301(2): C431-C440.

Aird WC. 2007. Phenotypic heterogeneity of the endothelium. Circ Res 100(2):158-173.

Aitsebaomo J, Portbury AL, Schisler JC, Patterson C. 2008. Brothers and sisters: molecular insights into arterial-venous heterogeneity. Circ Res 103(9):929-939.

Baechler EC, Batiwalla FM, Karypis G, Gaffney PM, Ortmann WA, Espe KJ, Shark KB, Grande WJ, Hughes KM, Kapur V, Gregersen PK, Behrens TW. 2003. Interferon-inducible gene expression signature in peripheral blood cells of patients with severe lupus. Proc. Natl. Acad. Sci. USA 100(5):2610-2615.

Chen Y, Huang K, Nakatsu MN, Xue Z, Deng SX, Fan G. 2013. Identification of novel molecular markers through transcriptomic analysis in human fetal and adult corneal endothelial cells. Hum Mol Genet 22(7):1271-1279.

Cheng X, Liu Y, Chu H, Kao HY. 2012. Promyelocytic leukemia protein (PML) regulates endothelial cell network formation and migration in response to tumor necrosis factoralpha (TNF alpha) and interferon-alpha (IFN alpha). J Biol Chem 287(28):23356-23367.

Craig LE, Spelman JP, Strandberg JD, Zink MC. 1998. Endothelial cells from diverse tissues exhibit differences in growth and morphology. Microvasc Res 55(1):65-76.

da Silva AJ, Brickelmaier M, Majeau GR, Lukashin AV, Peyman J, Whitty A, Hochman PS. 2002. Comparison of gene expression patterns induced by treatment of human umbilical vein endothelial cells with IFN-alpha $2 b$ vs. IFN-beta $1 a$ : understanding the functional relationship between distinct type I interferons that act through a common receptor. J Interferon Cytokine Res 22(2):173-188.

Denny MF, Thacker S, Mehta H, Somers EC, Dodick T, Barrat FJ, McCune WJ, Kaplan MJ. 2007. Interferon-\{alpha\} promotes abnormal vasculogenesis in lupus: a potential pathway for premature atherosclerosis. Blood 110(8):2907-2915.

Denny MF, Yalavarthi S, Zhao W, Thacker SG, Anderson M, Sandy AR, McCune WJ, Kaplan MJ. 2010. A distinct subset of proinflammatory neutrophils isolated from patients with systemic lupus erythematosus induces vascular damage and synthesizes Type I IFNs. J Immunol 184(6):3284-3297.

Eguchi K, Kawakami A, Nakashima M, Ida H, Sakito S, Matsuoka N, Terada K, Sakai M, Kawabe Y, Fukuda T. 1992. Interferon-alpha and dexamethasone inhibit adhesion of $\mathrm{T}$ cells to endothelial cells and synovial cells. Clin Exp Immunol 88(3):448-454.

El-Magadmi M, Bodill H, Ahmad Y, Durrington PN, Mackness M, Walker M, Bernstein RM, Bruce IN. 2004. Systemic lupus erythematosus: an independent risk factor for endothelial dysfunction in women. Circulation 110(4):399-404.

Erdmann J, Vitale G, van Koetsveld PM, Croze E, Sprij-Mooij DM, Hofland LJ, van Eijck CH. 2011. Effects of interferons alpha/beta on the proliferation of human micro- and macrovascular endothelial cells. J Interferon Cytokine Res 31(5):451-458.

Feng X, Wu H, Grossman JM, Hanvivadhanakul P, FitzGerald JD, Park GS, Dong X, Chen W, Kim MH, Weng HH, Furst DE, Gorn A, McMahon M, Taylor M, Brahn E, Hahn BH, Tsao BP. 2006. Association of increased interferon-inducible gene expression with disease activity and lupus nephritis in patients with systemic lupus erythematosus. Arthritis Rheum 54:2951-2962.

Goldenberg D, Olferiev M, Onat D, Harxhi A, Andrade D, Crow MK, Colombo P, Salmon JE. 2011. Analysis of 
endothelium from systemic lupus erythematosus patients demonstrates a marked interferon inducible signature and an associated decrease in transforming growth factor beta signaling genes. Arthritis Rheum 63(10):S562.

Gomez D, Reich NC. 2003. Stimulation of primary human endothelial cell proliferation by IFN. J Immunol 170(11):5373-5381.

Haque S, Rakieh C, Jackson MC, Alexander M, Bruce IN. 2009. Impaired endothelial progenitor cell function and early atherosclerosis in systemic lupus erythematosus (Sle). Rheumatology (Oxford) 48:I15.

Heathfield SK, Parker B, Zeef LA, Bruce IN, Alexander MY. 2013. Certolizumab pegol attenuates the pro-inflammatory state in endothelial cells in a manner that is atheroprotective. Clin Exp Rheumatol 31(2):225-233.

Hua J, Kirou K, Lee C, Crow MK. 2006. Functional assay of type I interferon in systemic lupus erythematosus plasma and association with anti-RNA binding protein autoantibodies. Arthritis Rheum 54:1906-1916.

Huang dW, Sherman BT, Lempicki RA. 2009. Systematic and integrative analysis of large gene lists using DAVID bioinformatics resources. Nat Protoc 4(1):44-57.

Kaiser WJ, Kaufman JL, Offermann MK. 2004. IFN-alpha sensitizes human umbilical vein endothelial cells to apoptosis induced by double-stranded RNA. J Immunol 172(3):1699-1710.

Lee PY, Li Y, Richards HB, Chan FS, Zhuang H, Narain S, Butfiloski EJ, Sobel ES, Reeves WH, Segal MS. 2007. Type I interferon as a novel risk factor for endothelial progenitor cell depletion and endothelial dysfunction in systemic lupus erythematosus. Arthritis Rheum 56(11):3759-3769.

Li JL, Deng H, Lai DB, Xu F, Chen J, Gao G, Recker RR, Deng HW. 2001. Toward high-throughput genotyping: dynamic and automatic software for manipulating large-scale genotype data using fluorescently labeled dinucleotide markers. Genome Res 11(7):1304-1314.

Moll HP, Maier T, Zommer A, Lavoie T, Brostjan C. 2011. The differential activity of interferon-alpha subtypes is consistent among distinct target genes and cell types. Cytokine 53(1):52-59.

Passerini AG, Polacek DC, Shi C, Francesco NM, Manduchi E, Grant GR, Pritchard WF, Powell S, Chang GY, Stoeckert CJ, Davies PF. 2004. Coexisting proinflammatory and antioxidative endothelial transcription profiles in a disturbed flow region of the adult porcine aorta. Proc Natl Acad Sci U S A 101(8):2482-2487.

Ribereau-Gayon G, Jung ML, Beck JP, Anton R. 1995. Effect of fetal calf serum on the cytotoxic activity of mistletoe (Viscum album L.) lectins in cell culture. Phytother Res 9(5):336-339.

Roldan CA, Joson J, Sharrar J, Qualls CR, Sibbitt WL Jr. 2010. Premature aortic atherosclerosis in systemic lupus erythematosus: a controlled transesophageal echocardiographic study. J Rheumatol 37(1):71-78.

Ruszczak Z, Detmar M, Imcke E, Orfanos CE. 1990. Effects of rIFN alpha, beta, and gamma on the morphology, proliferation, and cell surface antigen expression of human dermal microvascular endothelial cells in vitro. J Invest Dermatol 95(6):693-699.

Sgonc R, Fuerhapter C, Boeck G, Swerlick R, Fritsch P, Sepp N. 1998. Induction of apoptosis in human dermal microvascular endothelial cells and infantile hemangiomas by interferon-alpha. Int Arch Allergy Immunol 117(3):209-214.

Somers EC, Zhao W, Lewis EE, Wang L, Wing JJ, Sundaram B, Kazerooni EA, McCune WJ, Kaplan MJ. 2012. Type I interferons are associated with subclinical markers of cardio- vascular disease in a cohort of systemic lupus erythematosus patients. PLoS One 7(5):e37000.

Staton CA, Reed MWR, Brown NJ. 2009. A critical analysis of current in vitro and in vivo angiogenesis assays. Int J Exp Pathol 90(3):195-221.

Takase B, Uehata A, Fujioka T, Kondo T, Nishioka T, Isojima K, Satomura K, Ohsuzu F, Kurita A. 2001. Endothelial dysfunction and decreased exercise tolerance in interferonalpha therapy in chronic hepatitis C: relation between exercise hyperemia and endothelial function. Clin Cardiol 24(4): 286-290.

Thacker SG, Duquaine D, Park J, Kaplan MJ. 2010. Lupusprone New Zealand Black/New Zealand White F1 mice display endothelial dysfunction and abnormal phenotype and function of endothelial progenitor cells. Lupus 19(3):288-299.

Thacker SG, Zhao W, Smith CK, Luo W, Wang H, Vivekanandan-Giri A, Rabquer BJ, Koch AE, Pennathur S, Davidson A, Eitzman DT, Kaplan MJ. 2012. Type I interferons modulate vascular function, repair, thrombosis, and plaque progression in murine models of lupus and atherosclerosis. Arthritis Rheum 64(9):2975-2985.

Tissari J, Siren J, Meri S, Julkunen I, Matikainen S. 2005. IFNalpha enhances TLR3-mediated antiviral cytokine expression in human endothelial and epithelial cells by up-regulating TLR3 expression. J Immunol 174(7):4289-4294.

Trinchieri G. 2010. Type I interferon: friend or foe? J Exp Med 207(10):2053-2063.

Ueyama H, Sasaki I, Shimomura K, Suganuma M. 1995. Specific protein interacting with a tumor promoter, debromoaplysiatoxin, in bovine serum is alphal-acid glycoprotein. $\mathrm{J}$ Cancer Res Clin Oncol 121(4):211-218.

Wada H, Nagano H, Yamamoto H, Noda T, Murakami M, Kobayashi S, Marubashi S, Eguchi H, Takeda Y, Tanemura M, Umeshita K, Doki Y, Mori M. 2009. Combination of interferon-alpha and 5-fluorouracil inhibits endothelial cell growth directly and by regulation of angiogenic factors released by tumor cells. BMC Cancer 9(1):361.

Wang J, Chen H, Shankowsky HA, Scott PG, Tredget EE. 2008. Improved scar in postburn patients following interferonalpha $2 b$ treatment is associated with decreased angiogenesis mediated by vascular endothelial cell growth factor. J Interferon Cytokine Res 28(7):423-434.

Ward MM. 1999. Premature morbidity from cardiovascular and cerebrovascular diseases in women with systemic lupus erythematosus. Arthritis Rheum 42(2):338-346.

Wittstock M, Rehfeldt C, Mix E, Zettl UK. 2001. Comparison of three different proliferation assays for mouse myoblast cultures. Anal Biochem 292(1):166-169.

Address correspondence to: Dr. John Andrew Reynolds Arthritis Research UK Epidemiology Unit Institute of Inflammation and Repair Manchester Academic Health Sciences Centre The University of Manchester Manchester M13 9NT United Kingdom

E-mail: john.reynolds@manchester.ac.uk

Received February 5, 2013/Accepted October 25, 2013

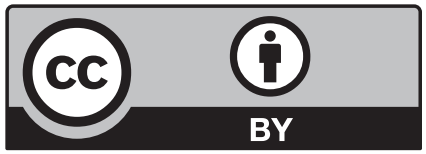

This work is licensed under a Creative Commons Attribution 3.0 United States License. You are free to copy, distribute, transmit and adapt this work, but you must attribute this work as "Journal of Interferon and Cytokine Research. Copyright 2013 Mary Ann Liebert, Inc. http://liebertpub.com/jir, used under a Creative Commons Attribution License: http://creativecommons.org/licenses/by/3.0/us/", 